cooperation. Supported by NIH Grants HD01490, K5-MH-21762, and FR00249. J.C.J. is an NIH predoctoral fellow and K.M.B. and W.K.B. are NIH predoctoral trainees.

2. Present address: Children's Asthma Research Institute and Hospital, Denver, Colo. 80204.

3. Present address: Department of Child Development and Family Life, Purdue University, Lafayette, Ind. 47907.

4. Sokolov (1963) claimed that "orienting reflexes" could be "reinstated" during sleep, but the response he described better meets his criteria of a "defensive reflex" since it was nonhabituating and included cephalic vasoconstriction (p. 122).

5. Berg, K. M., Berg, W. K., \& Graham, F. K. Infant heart rate response as a function of stimulus and state. Unpublished manuscript, 1970

6. For computational convenience, equal numbers of $S s$ were obtained at each age by including only the first 12 adult Ss in the analysis of age effects.

\section{The effect on retention of successive recall trials before unlearning}

\author{
GERALD LAZAR, State University \\ College, New Paltz, N.Y. 12561
}

Successive recall trials (present or absent) after first list learning was factored against an unlearning condition (present or absent). While unlearning retarded retention, successive recall did not reliably counteract the unlearning effect.

Successive recall trials might be characterized as repetition without overt reinforcement. It is a procedure in which the stimulus members of paired associates are presented as cues for second-member recall and $S$ is given no information regarding the correctness of his responses, i.e., the response members are omitted. Two alternative hypotheses have recently been suggested about the effect of successive recall trials: (1) they lead to an increase of associative strength (Richardson \& Gropper, 1964), and (2) they affect availability rather than associative strength (Lazar, 1969). In most retention studies, these hypotheses would lead to the same prediction. They can, however, be differentiated in an unlearning situation. In this experiment, successive recall trials follow first list (A-B) learning. If successive recall trials strengthen $A-B$ associations, then the unlearning effect ought to be reduced and groups with successive recall following A-3 learning would have better $A \cdot B$ recall than control groups. However, if successive recall merely makes A-B associations more available, then the learned associations should be more easily elicited during A-C learning, thereby resulting in more unlearning (Postman, 1965). Thus, within the unlearning paradigm the availability hypothesis predicts less A-B recall, while the associative strengthening hypothesis, in conjunction with the elicitation hypothesis of unlearning, predicts greater A-B recall for groups receiving successive recall trials after A-B learning and prior to A-C acquisition.

\section{DESIGN}

The design of the experiment was a 2 by 2 factorial varying the presence or absence of successive recall trials after A-B learning and the presence or absence of an unlearning task (A-C vs D-C) after recall.

\section{MATERIALS}

Three lists of 10 paired associates were constructed. The A-B list was constructed using high-frequency $(\mathrm{A}, \mathrm{AA})$ words from the Thorndike-Lorge (1944) word count. They were paired randomly with the restrictions that (1) there be no obvious associations between members of a pair, and (2) that no members of a pair have the same initial letter. The same restrictions were observed in the construction of the remaining lists. The A-C list was composed of the same stimulus items as the A-B list. The response members were either the first or second associate to 10 of the Cohen, Bousfield, \& Whitmarsh (1957) category names. The D-C list was composed of stimulus members selected from the Thorndike-Lorge word count (A, AA) and the response items were the same as those appearing in the A-C list.

\section{TRAINING}

The alternating training-test method was used. There were three orders of training and testing to minimize serial learning. Material was presented with a slide projector at a $2.5-\mathrm{sec}$ rate. A 4-sec interval separated training and test phases, and six training and test trials were given on each list. After A-B acquisition, the groups receiving successive recall trials were given six trials of stimulus presentation at the same rate as in training and were asked to recall the responses aloud. They were given no information about the correctness of their responses. The stimulus items for the successive recall trials appeared in the same three orders used in training. The groups without successive recall after training were given about $3 \mathrm{~min}$ of a filler activity consisting of sorting playing cards into suits, naming aloud each card as it was sorted. After successive recall trials or the filler activity, all groups received six trials of training and testing on either the A-C or the D.C list. The retention test immediately followed the last test trial of second-list acquisition.

\section{RECALL}

A modified modified-free-recall test was used to measure retention. Ss were given a sheet of paper on which the $A$ items were printed in a column. To the right of each $A$ item, two blank lines were printed. Ss were instructed to write the words that had been paired with the $A$ iterns. They were not asked to indicate what lists the items came from. They were allowed to fill in the items in any order and they were given unlimited time for the task.

\section{SUBJECTS}

The Ss were 60 experimentally naive undergraduate volunteers from general psychology classes who were given extra course credit for taking part in the experiment. They were assigned randomly to each of the four treatments in the order that they appeared in the laboratory, except for the restriction that there be 15 Ss in each condition.

\section{RESULTS}

All analyses were based on the number of correct A-B responses. The mean correct responses given on the last test trial of acquisition and on recall, and their difference scores, are displayed in Table 1. A two-way analysis of variance on the number of correct responses given on the last $A \cdot B$ test trial yielded an $F$ of 7.43 $(\mathrm{df}=1 / 56)$ on the unlearning factor, which was barely significant at the .05 level. The $F$ for successive recall and the $F$ for the Successive Recall by Unlearning interaction were both less than 1. An Fmax test for heterogeneity of variance yielded 8.19 , which was significant beyond the .01 level. Therefore, it was decided to analyze the recall data as difference scores between the number of correct responses on the last trial of testing during A-B acquisition and on MMFR. A square-root transformation was performed on these difference scores. 
Table 1

Mean Correct First-List Responses on the Last Test Trial of Acquisition, on Modified Modified-Free-Recall, and the Mean Difference Scores Between Them

\begin{tabular}{lccr}
\hline Group & Last OL & Recall & Difference \\
\hline AB AC & 7.87 & 5.53 & -2.33 \\
AB SRC AC & 7.73 & 7.07 & -.66 \\
AB DC & 9.00 & 8.87 & -.13 \\
AB SRC DC & 9.20 & 9.27 & +.07 \\
\hline
\end{tabular}

A two-way analysis of variance on the transformed difference scores yielded an $F$ of 15.70 on the unlearning factor, which was significant beyond the .01 level $(d f=1 / 56)$. Neither the $F$ for successive recall nor the $F$ for the Successive Recall by Unlearning interaction were significant $(F=5.86$ and $F=3.92$, respectively, df $=1 / 56)$.

\section{DISCUSSION}

Successive recall after first-list learning did not seem to have any statistically reliable effect on later retention, whereas unlearning did. However, there does seem to be a tendency for greater retention loss for the group with unlearning but without successive recall trials, suggesting some support for the associative strength hypothesis. Perhaps more successive recall trials would have yielded statistically significant effects on retention. Whether successive recall strengthens associative bonds or whether it facilitates the retrieval of responses remains undetermined.

Extending successive recall procedures into the unlearning area could well be a way to separate the availability hypothesis from the associative strength hypothesis, both of which usually make similar predictions regarding recall. Further research on successive recall might also help to clarify the role of repetition and reinforcement in learning and retention.

\section{REFERENCES}

COHEN, B. H., BOUSFIELD, W. A., \& WHITMARSH, G. A. Cultural norms for verbal items in 43 categories. Technical Report No. 22, University of Connecticut, Contract Nonr $631(00)$ ONR, 1957.

LAZAR, G. Retention as a function of successive recall trials following original learning. Psychological Reports, 1969, 25, 567-574.

POSTMAN, L. Unlearning under conditions of successive interpolation. Journal of Experimental Psychology, 1965, 70, 237-245.

RICHARDSON, J., \& GROPPER, M. S. Learning during recall trials. Psychological Reports, 1964, 15, 551-560.

THORNDIKE, E. L., \& LORGE, I. The teachers word book of 30,000 words New York: Bureau of Publications, Teachers College, Columbia University, 1944.

\section{NOTES}

1. This study was supported in part by a grant from the SUNY Research Foundation.

2. The author thanks Stewart Gordon for his help in collecting data. 